\title{
Indigenous Knowledge in Environmental Assessment
}

\author{
MARC G. STEVENSON ${ }^{1}$
}

(Received 24 October 1995; accepted in revised form 30 April 1996)

\begin{abstract}
Increasingly, federal environmental guidelines require developers to consider the "traditional knowledge" of aboriginal people in assessing the impact of proposed projects on northern environments, economies, and societies. However, several factors have limited the contributions of traditional knowledge to environmental impact assessment (EIA) in the North, including confusion over the meaning of this term, who "owns" this knowledge, and its role in EIA. The term "indigenous knowledge," which comprises traditional and nontraditional, ecological and nonecological knowledge, is proposed as an alternative that should allow aboriginal people, and the full scope of their knowledge, to assume integral roles in EIA.

Experience gained in attempting to give aboriginal people a voice and an assessment role in the diamond mine proposed by BHP Diamonds Inc. at Lac de Gras in the Northwest Territories has led to the development of a multiphased, holistic approach to involving aboriginal people and their knowledge in EIA. Because of their in-depth knowledge of the land, aboriginal people have a particularly important role to play in environmental monitoring and distinguishing project-related changes from natural changes in the environment. However, the strengths of traditional and Western scientific knowledge in EIA will not be realized until both are recognized as parts of a larger worldview that influences how people perceive and define reality.
\end{abstract}

Key words: aboriginal people, indigenous knowledge, environmental impact assessment, traditional knowledge, traditional ecological knowledge, valued ecosystem components, Western scientific knowledge, participatory action research

RÉSUMÉ. De plus en plus, les lignes directrices environnementales du gouvernement fédéral exigent des responsables de projets de développement qu'ils tiennent compte du «savoir traditionnel» des peuples autochtones en évaluant les incidences des projets à l'étude sur les milieux, les économies et les sociétés nordiques. Toutefois, plusieurs facteurs ont limité la contribution du savoir traditionnel à l'évaluation des incidences environnementales (EIE) dans le Grand Nord, y compris l'ambiguïté entourant le sens de cette expression, la personne qui «détient» ce savoir, et son rôle dans l'EIE. On propose l'emploi de l'expression «savoir autochtone», qui englobe savoir traditionnel et non traditionnel, savoir écologique et non écologique, comme une solution qui permettrait aux peuples autochtones, ainsi qu'à toute la dimension de leur savoir, d'assumer un rôle intégral dans l'EIE.

L'expérience acquise lors des efforts en vue de donner une voix et un rôle d'évaluateurs aux autochtones dans le projet d'exploitation de la mine diamantifère de BHP Diamonds Inc. à Lac de Gras (Territoires du Nord-Ouest) a conduit à une approche holistique, à facettes multiples, qui vise à faire participer les autochtones et leur savoir à l'EIE. En raison de leur connaissance approfondie de la terre, les autochtones ont un rôle particulièrement important à jouer dans le contrôle de l'environnement et la distinction entre les changements environnementaux dus aux projets et ceux dus à la nature. Toute la force du savoir traditionnel et des connaissances scientifiques occidentales ne se manifestera toutefois que lorsqu'on admettra que les deux parties participent à une vision du monde élargie qui influence la façon dont les individus définissent la réalité.

Mots clés: peuples autochtones, savoir autochtone, évaluation des incidences environnementales (EIE), savoir traditionnel, savoir écologique traditionnel, composants valorisés d'un écosystème, connaissances scientifiques occidentales, recherche-action participative

Traduit pour la revue Arctic par Nésida Loyer.

\section{INTRODUCTION}

Those who live on the land and harvest its resources have an intimate knowledge of the distribution of resources, the functioning of ecosystems, and the relationship between the environment and their culture. For many questions that are raised in the Guidelines, traditional knowledge will have as important a contribution to make as scientific and engineering knowledge. The proponent should fully consider local traditional knowledge and expertise in preparing the Environmental Impact Statement. (BHP

Diamond Mine Environmental Assessment Panel, 1995)

For many centuries, the socioeconomies of Canada's aboriginal peoples have been based on an intimate understanding of and relationship with the natural world. However, only recently has their knowledge been considered a necessary component of environmental assessment (e.g., Johannes, 1993). Part of this acknowledgement stems from the pursuit of political and property rights by aboriginal groups around

${ }^{1}$ Canadian Circumpolar Institute, University of Alberta, 8820 - 112th Street, Edmonton, Alberta T6G 2E2, Canada

(C) The Arctic Institute of North America 
the world and the recognition of these rights by nation states. The rights of aboriginal people to fully participate in decisions concerning developments that affect their lands, cultures, and lifestyles have also been recognized in international agreements (e.g., Agenda 21, United Nations Conference on Environment and Development, 1992). At the same time, growing recognition of the limits of conventional science in solving ecological problems of increasing complexity and magnitude has also resulted in calls for the incorporation of traditional ecological knowledge and practices into resource management and development (Wolfe et al., 1992). The industrialized world may, in fact, have much to learn from indigenous peoples about the sustainable use of natural resources:

[Lifestyles of tribal and indigenous peoples] can offer modern societies many lessons in the management of resources in complex...ecosystems. (World Commission on Environment and Development [WCED], 1987:12)

Their disappearance is a loss for the larger society, which could learn a great deal from their traditional skills in sustainably managing very complex ecological systems. (WCED, 1987:114-115)

A number of international arctic agreements, including the Arctic Environmental Protection Strategy (Inuit Circumpolar Conference [ICC], 1993), have recognized that over many generations northern aboriginal people have developed holistic knowledge of their lands and natural resources, which can contribute significantly to environmentally sound and sustainable development practices.

In an effort to assess the environmental, social, and economic impacts of large-scale developments on northern lands and communities, federal environmental guidelines have begun to require that developers incorporate the "traditional knowledge" of aboriginal people into environmental impact assessment (EIA). Such guidelines are an important step towards ensuring that the concerns of Canada's northern aboriginal people will be fully and meaningfully considered. This can only lead to improved decision making in the assessment and management of environmental impacts, and to increased benefits for northern communities.

Yet, the role of traditional knowledge in EIA in the North is often not adequately understood or appreciated by government and industry, partly because this requirement is relatively new, and few examples exist to serve as models, but also because many non-aboriginal people do not appreciate how their knowledge system differs from that of aboriginal people. Thus, there appears to be a general misunderstanding of what traditional knowledge is, how it is constructed and what role it has in EIA.

Dene, Inuit, and Metis often raise concerns in environmental hearings about the impacts of development on their lands and communities. Aboriginal peoples' concerns derive principally from three sources: 1) traditional ecological knowledge (TEK), most notably, knowledge of ecosystem relationships and appropriate behaviours governing the use of resources; 2) past experience with northern industrial developments (e.g., hydro, oil and gas, and mining); and 3) a lack of specific knowledge about proposed developments and how these may affect aboriginal lands and lifestyles, especially valued ecosystem components and relationships. It is the documentation of such concerns, not the construction of traditional knowledge baselines, that must be viewed as the first step in an ongoing process of involving aboriginal people and incorporating their knowledge into environmental assessment and management in Canada's North. An exclusive focus on the documentation of TEK for the construction of baseline data in EIA may create a potentially exploitive situation; this knowledge may be taken out of context or misinterpreted by current and subsequent developers. This risk is even greater when aboriginal people have little control over how their knowledge is documented, interpreted, and used. Thus, the possibility for industry to use the knowledge of northern aboriginal people in ways that do not serve their interests is great, particularly in regions where land claims and treaty entitlements are still being negotiated.

On the other hand, aboriginal people may derive considerable benefit from documenting their knowledge and applying it in the context of EIA. Aside from the specific contributions that traditional knowledge can make to EIA, many aboriginal groups in Canada's North recognize that by recording this knowledge and passing it on to younger generations, they can slow down and even reverse the erosion of their cultural identities, values, and customs. In addition, this documentation creates opportunities for aboriginal participation in development and environmental policies. Nonetheless, the use of such knowledge in EIA may also promote goals incompatible with aboriginal needs and lifestyles. This realization has prompted some aboriginal groups and organizations to establish explicit guidelines for the use of their traditional knowledge (e.g., Yellowknives Dene First Nation, 1995a).

This paper explicitly advances a process for meaningfully involving aboriginal people and incorporating their knowledge into EIA that will benefit both aboriginal people and industry. Industry need not be incompatible with aboriginal lifestyles, and industrial capitalism does not have to destroy aboriginal economies. Mines have the potential to strengthen aboriginal lifestyles by providing aboriginal people with much-needed cash income and time off to pursue their traditional land-based activities (e.g., a two weeks on/two weeks off shift rotation has been adopted by Echo Bay Mines Ltd. Lupin mine at Contwoyto Lake and has been proposed for BHP's diamond mine at Lac de Gras). In the Northwest Territories today, hunting and other traditional forms of subsistence require large amounts of money for equipment and supplies, and aboriginal people need jobs to maintain these lifestyles. By providing aboriginal people with the money and opportunity to carry on their traditional landbased activities, mines can support the skills required to live off the land and help ensure the transfer of aboriginal knowledge, customs, values, and traditions to future generations. Aboriginal elders recognize that mining can contribute 
significantly to sustainable development in northern regions:

I've only been to the Lupin mine and the effects of that you see in the community. You see all the people that work for the mines...they have snowmobiles now and fourwheelers, boats, and motors, something to go out and have fun with out on the land. Before working for the mine, some of these people were on social assistance, and now they're being more independent; they have machines to go out hunting and for their kids to go out hunting with. (Miyok, 1995:7)

[Work] encourages young people to buy skidoos and boats and motors with the wages. That helps their parents [and] maintains their connection with the land. That strengthens the family too. Elders are encouraging youth to get training and education before the mine goes in.... (Migwi, 1995)

Given the potential benefits of mining to Northerners, both developers and aboriginal people would benefit greatly by agreeing on an approach to meaningfully involving the latter and their knowledge in environmental assessment and management. To help develop such a process, this paper begins by discussing the structural components of the knowledge of aboriginal people and the interrelationships among those components.

\section{TRADITIONAL OR CONTEMPORARY? THE STRUCTURE OF INDIGENOUS KNOWLEDGE}

If the words 'traditional Inuit knowledge' are supposed to include everything we know about everything, it looks to me as though we probably don't know too much.... (J.N. Kangirsuk; ICC, 1993:35)

Traditional knowledge? Never heard of it. I didn't even know I had it. What's the world thinking of it for? (Adamie; in Gombay, 1995:81)

Dene, Inuit, and Metis in Canada's North possess knowledge that is not just "traditional," but contemporary. In fact, it can be argued that all knowledge is contemporary, for it is given meaning and value from a frame of reference that is continually being updated and revised. Many aboriginal people feel that requests to access their traditional knowledge represent just another form of exploitation (Yellowknives Dene First Nation, 1995a), because this knowledge can be easily taken out of context and misrepresented. Moreover, viewing the knowledge that aboriginal people possess as essentially traditional invites denial of the relevance and efficacy of applying their knowledge to present-day issues and problems. Thus, aboriginal people sometimes feel that the term "traditional" imposes a way of life on them that is shackled to the past and does not allow them to change (Gombay, 1995:22). Such a view can only perpetuate the muted status of aboriginal people both in EIA and in restructuring their present social, economic, and political conditions.

\section{Indigenous Knowledge}

A more appropriate term for the knowledge, experiences, wisdom, and philosophies that aboriginal people can bring to bear on environmental assessment and management is "indigenous knowledge." This term, which is beginning to find favour with aboriginal organizations (e.g., ICC, 1993) and academics alike (e.g., Wolfe et al., 1992; Gombay, 1995), is less contentious, more inclusive, and thus more empowering than "traditional knowledge." Further, it does not invite misappropriation in the way that "traditional knowledge" does. Nonetheless, "indigenous knowledge" still does not capture the full content or context of the knowledge that most aboriginal people possess. For purposes of environmental assessment, as well as for harvest assessment and co-management, which also try to incorporate aboriginal ecological knowledge into decision making, indigenous knowledge can be viewed as having two sources: traditional knowledge and nontraditional knowledge. This perspective acknowledges two facts: 1) that aboriginal people also possess knowledge and experiences not grounded in traditional lifestyles, spirituality, philosophy, social relations, and cultural values; and 2) that indigenous knowledge is the articulation, and frequently the dialectic, of traditional and nontraditional knowledge (Fig. 1).

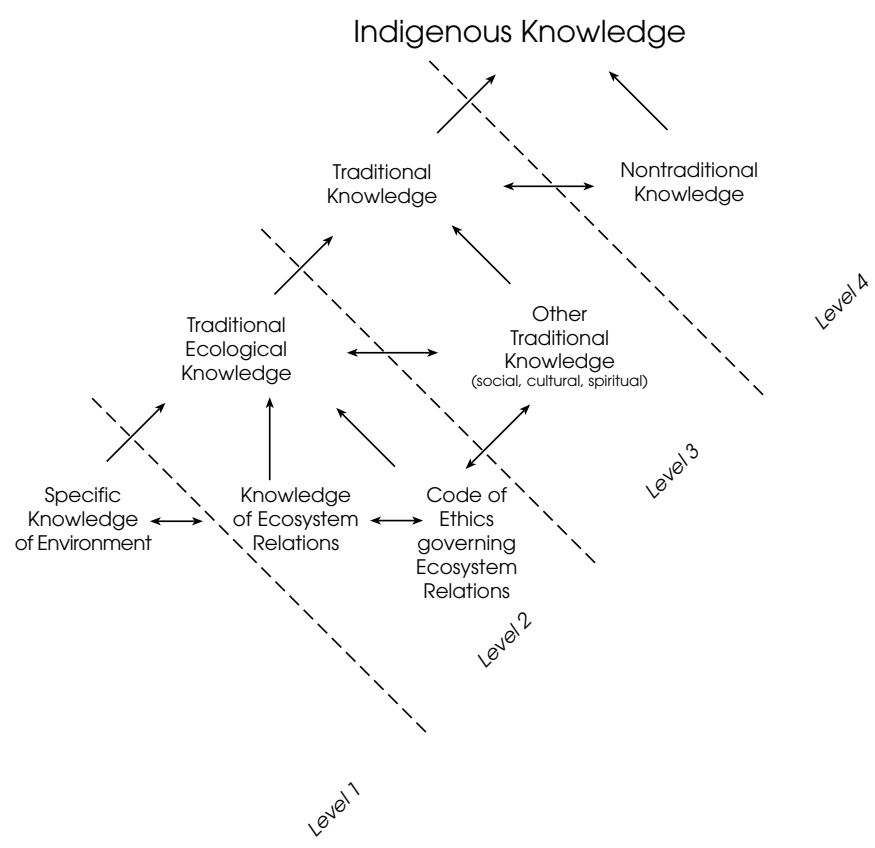

FIG. 1. Structural components of indigenous knowledge, with varying levels of incorporation into environmental assessment and management.

While different, these sources of knowledge share some features in common. For example, rules and knowledge for living in a social context may be similar. Yet, crucial 
distinctions reflect different philosophical traditions and perceived realities. For example, traditional aboriginal philosophies emphasize extensive knowledge of and codes for living in harmony with nature. Western philosophical tradition lacks such considerations. Indeed, such aboriginal philosophies may contribute significantly to the sustainable utilization of the earth's resources, and thus to human survival on this planet. Perhaps as a consequence, Western scientific tradition has become more accepting of holistic viewpoints over the past decade.

Nontraditional Knowledge: Most aboriginal people possess an extensive base of nontraditional knowledge derived from their interaction with non-aboriginal people and institutions; television and other modern media; formal schooling in numeracy and literacy; the adoption of Western scientific thinking; and exposure to foreign values, attitudes, and philosophies. In contrast, traditional knowledge systems are based on the shared experiences, customs, values, traditions, subsistence lifestyles, social interactions, ideological orientations, and spiritual beliefs unique to aboriginal communities. Together, these two foundations of knowledge articulate to form a worldview, a frame of reference, understanding, and validation, that provides meaning and value to the lives of contemporary aboriginal peoples (Fig. 1).

For government and industry to concentrate on traditional knowledge in EIA, to the exclusion of indigenous knowledge, serves neither their interests nor those of aboriginal people. Often, aboriginal people whose understandings are constructed from both systems of knowledge can offer invaluable insights into assessing the full impact of northern development on the ecosystem components and relations they consider important, or "valued ecosystem components" (VECs). Not only have many aboriginal people experienced both traditional and nontraditional realities and lifestyles, and felt directly the impact of industrial development, but they have already worked out many of the conflicts between the two systems of knowledge in their own minds. Thus, their resolution of the two knowledge systems for any given issue can provide insights into EIA that neither system alone could offer. This can only lead to more refined explanations and better understandings of environmental impacts.

Traditional Knowledge: Traditional knowledge may be viewed as being composed of "traditional ecological knowledge" (TEK) and other kinds of traditional knowledge not immediately related to or dependent upon the environment for reference or validation. Even though environment and society are intimately related, if not inseparable, in the minds of many aboriginal people whose lifestyles and identities still derive from their connection to the land, TEK and other kinds of traditional knowledge are distinguished here for purposes of discussion.

Traditional Ecological Knowledge (TEK): TEK may be viewed as being composed of three interrelated components: 1) specific environmental knowledge, 2) knowledge of ecosystem relationships, and 3) a code of ethics governing appropriate human-environmental relationships (Fig. 1). TEK is frequently the base of knowledge that many non-aboriginal people interpret as traditional knowledge. While the Dene Cultural Institute (DCI) defines TEK as "traditional environmental knowledge," such knowledge is constructed of much more than just knowledge pertaining to the environment:

Traditional environmental knowledge is a body of knowledge and beliefs transmitted through oral tradition and first-hand observation. It includes a system of classification, a set of empirical observations about the local environment and a system of self-management that governs resource use. Ecological aspects are closely tied to social and spiritual aspects of the knowledge system. The quantity and quality of TEK varies among community members, depending upon gender, age, social status, intellectual capability and profession (hunter, spiritual leader, healer, etc.). With its roots firmly in the past, TEK is both cumulative and dynamic, building upon the experience of earlier generations and adapting to the new technological and socioeconomic changes of the present. (DCI, 1995a:2)

While this definition may be so broad as to confound rather than clarify, its value derives from showing how TEK accommodates change and innovation, and how it is embedded in a system of knowledge that has broader social, economic, and spiritual dimensions. Thus, TEK cannot be properly understood or applied without reference to these dimensions.

For present purposes, knowledge related to various species of wildlife, plants, land-use patterns, seasons, climate, hydrology, and geomorphology are included under specific environmental knowledge. This is the knowledge that is most attractive to, and sought after by, non-aboriginal people for use in EIA, harvest assessment, and environmental co-management, as it is the most accessible and comprehensible in terms of our Western system of knowledge.

Knowledge of the interactions and relationships between and among environmental components constitutes a second component of traditional ecological knowledge. The relationship between specific environmental knowledge and ecological knowledge is not unlike the differences between the "species approach" and "ecosystems approach" of biologists. The focus of the latter is on the relationships among components and the operation of the ecosystem, rather than the specific components themselves.

A code of ethics governing appropriate use of the environment and the maintenance of appropriate ecosystem relationships constitutes a third category of knowledge subsumed under TEK. Indeed, in the minds of many aboriginal elders, humans play a significant role in maintaining key ecosystem relationships. This code includes rules and conventions promoting both desirable human-nature relationships and appropriate human-human relationships, since aboriginal social relations and cultural identity were and continue, in part, to be established, reaffirmed, and validated primarily through productive activity on the land. It is this code of ethics component of TEK which is easily blurred with knowledge subsumed under the category "other traditional knowledge." 
Other Traditional Knowledge: Many aboriginal people have acquired a rich and extensive base of traditional knowledge that, although not independent of ecological knowledge, does not require continual reference to or validation by it. Such knowledge includes that which traditionally informed emotional and physical well-being, customary social values, cultural practices, and spiritual beliefs (Fig. 1). Again, while all aspects of indigenous knowledge are interconnected, and thus related to the natural environment, it is also important to understand the different contexts that give such knowledge meaning and value.

The above discussion demonstrates that attempts to analyze and dissect the knowledge systems of aboriginal people, however well intended, fail to capture the true richness, complexity, and contextuality of such systems. Efforts to pigeonhole the various components of indigenous knowledge may be doomed from the start, simply because aboriginal people have traditionally held a holistic (or cosmocentric) view of the world. In this worldview, humans perceive themselves as being one link-albeit an integral one-in maintaining the balance of nature. Differences between traditional aboriginal and Western scientific philosophies and knowledge systems are discussed below.

\section{INDIGENOUS KNOWLEDGE IN ENVIRONMENTAL ASSESSMENT}

How might indigenous knowledge and its various components, including TEK, be best incorporated into EIA in order to satisfy both the needs of developers and the interests of aboriginal people? This is the challenge faced by both parties. Unfortunately, many government agencies and nongovernment organizations view references to traditional knowledge in federal environmental guidelines as an opportunity to construct comprehensive regional databases of TEK for purposes of EIA. These knowledge bases would be used not only to assess the environmental impacts of the proposed project, but to fill in knowledge gaps identified by government and industry, and to evaluate the effects of subsequent developments.

However, this view is inadequate for two reasons. First, it fails to acknowledge that the ecological knowledge of aboriginal people is contextual, dynamic, and forever being revised. Second, in this view, traditional ecological knowledge is given no role whatsoever in identifying VECs, impacts on these VECs, or knowledge gaps relevant to these VECs. The ecological knowledge of aboriginal people should not be a "handmaiden" to the needs and interests of the dominant culture; rather, it should play a predominant role in identifying impacts and devising strategies to mitigate them. How this knowledge is collected, interpreted, and applied, and by whom, should remain under the exclusive control of aboriginal groups who are in the best position to document this knowledge and to share it with outside interest groups, if they so choose.

TEK will undoubtedly contribute significantly to an overall understanding of environmental phenomena and ecological relationships in areas of proposed northern development throughout the circumpolar world. However, "full and equal consideration" of both traditional knowledge and indigenous knowledge in EIA is difficult to achieve under current aboriginal-nation state arrangements. This fact is well known to various co-management boards composed of aboriginal people and non-aboriginal managers: inevitably, the latter do most of the managing and the former most of the cooperating (ICC, 1994:17). With few exceptions, researchers and managers with little understanding of aboriginal cultures, realities, or knowledge systems have taken the knowledge of aboriginal people out of context. Forced to communicate their concepts and understandings of the environment and their place in it in the language of the dominant ideology (e.g., wildlife management), aboriginal people are often placed in a subordinate position. Subsequently, it is easy for such information to be reinterpreted or given a meaning different from that which gave value and significance to such knowledge in the first place. Many aboriginal people view this extraction of their knowledge from its original sociocultural context as a form of theft and, understandably, have been reluctant to share the depth and breadth of their knowledge with outsiders. Thus, attempts to document TEK by nonaboriginals have tended to result in either inventories of elements or simple descriptions of natural processes couched in scientific terms.

The incorporation of indigenous knowledge into environmental assessment and management has yet to progress to a level that adequately realizes its potential value and contributions to such activities. Often, only the "facts" or elements of TEK, as they are perceived by managers, are incorporated into management decisions. At this level (Level 1 in Fig. 1), no consideration is given to the broader meaning or value of these facts in the context of a coherent, organized system of ecological thought and understanding. As interpretations of these facts are usually based on the dominant scientific mode, a significant power imbalance exists at this level.

Level 2 incorporates and uses for decision making the entire system of TEK, including both knowledge of ecosystemic relationships and the code of ethics and beliefs governing these relations (Fig. 1). Regrettably, very few cooperative management plans and actions have progressed to this level. A notable exception is the co-management plan that was recently accepted by the Department of Fisheries and Oceans (DFO) and the Nunavut Wildlife Management Board to resolve fundamental disagreements between Inuit hunters and government biologists about the status of beluga whales in the southeast Baffin area (DFO, 1994). In this plan, both parties adopted new concepts and terms that facilitated mutual respect for each other's perspectives and interpretations, and thus recognition of the role of Inuit ecological knowledge in resolving the issue.

Level 3 incorporates not just the system of TEK, but other aspects of traditional knowledge (e.g., social rules, spirituality, health, etc.), and thus the entire system of holistic traditional knowledge, including aboriginal wisdom and philosophy. Insofar as the latter constitutes a distinctive, complexly 
articulated understanding of life and the world, piecemeal extraction of knowledge from this context may alienate aboriginal people from their cultural roots, thus contributing to the erosion of cultural values and identities.

Finally, level 4 incorporates and uses as a basis for decision making not just traditional knowledge, but also nontraditional knowledge and the articulation of the two: in other words, all sources of indigenous knowledge. At this level, definitions and the validation of indigenous knowledge by government and industry become irrelevant, for here the knowledge of aboriginal people is given full and equal consideration, alongside scientific and engineering knowledge, in environmental assessment and management. As all other levels invite the misappropriation and decontextualization of indigenous knowledge from its cultural context, it is at this fourth level that the incorporation of the knowledge of aboriginal people into EIA must take place.

The misrepresentation of TEK is the concern that lies behind many aboriginal peoples' reluctance to share their knowledge in the context of EIA:

Since [we] indigenous peoples have our own worldview...we feel that no industrial developer should be expected to collect, interpret and present the views and concerns, the knowledge, or the understanding of indigenous peoples. Instead, indigenous peoples should be given the opportunity to document and present our circumstances and our own evaluation of potential impacts from major developments on our people, culture, and lands....When Western scientists include the knowledge of selected local people in their studies, our people are passive contributors, and our knowledge, removed from our people's worldview, is subjected to interpretation through the Western worldview. (Yellowknives Dene First Nation, 1995b:7, 8)

The potential to take the knowledge of aboriginal people out of context is also the reason that the Dene Cultural Institute has advanced such a broad definition of TEK (DCI, 1995a). However, not all indigenous knowledge is traditional, and to say it is so places undue burden on developers, while shackling aboriginal people to their past. This can only undermine the potential contributions of aboriginal people and their knowledge to environmental assessment and management.

\section{Realizing the Contributions of Aboriginal People and Their Knowledge to EIA}

Although TEK may contribute to an overall understanding of the environmental impacts of a proposed project, its documentation in a careless and insensitive manner may also contribute to the alienation of aboriginal people from the very systems of knowledge, social practices, and cultural frameworks they seek to preserve. On the other hand, fuller contributions of aboriginal people and their knowledge to environmental assessment and management can be realized by 1) having aboriginal people document their concerns, including the reasons for such concerns, about the anticipated environmental, social, and economic impacts of a proposed project; 2) mitigating these concerns to the satisfaction of both the aboriginal people of the region and federal regulations; and 3) designing specific programs to fully involve aboriginal people and incorporate their knowledge into subsequent monitoring of VECs and managing of impacts over the long term (Fig. 2).

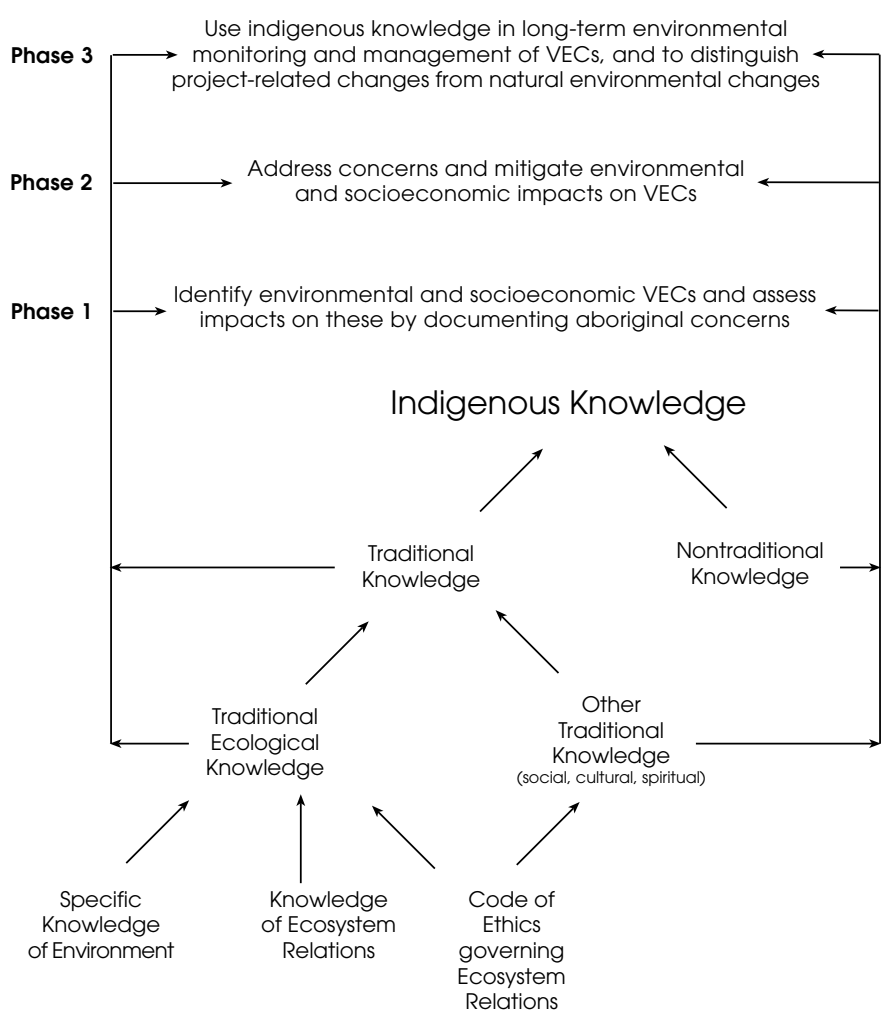

FIG. 2. The phases and roles of various components of indigenous knowledge in environmental assessment and management.

Phase One: The involvement of aboriginal people and incorporation of their knowledge into EIA in the North begins when those aboriginal communities most directly affected by proposed development identify what is important to them and why. In other words, it starts with the identification of valued ecosystem components (VECs) from an aboriginal perspective. The process of determining these VECs begins with community consultations and continues through to a direct exchange of information between developers and with target groups and individuals selected by the community members themselves.

This process allows the range of concerns expressed by aboriginal communities about these VECs to be properly documented. By documenting their concerns, aboriginal people participate directly and effectively in impact prediction and assessment. Concerns, as noted above, are based on what people know, what they have experienced, or what they fear might happen in the future. Moreover, this process does not arbitrarily limit the contributions of aboriginal people in EIA 
to "traditional knowledge," as current regulations do. Rather, it enables them, if they so choose, to share all relevant indigenous knowledge. Aboriginal people also remain in control of this knowledge and share only that which informs their concerns and possible impacts, considerably reducing the potential for a developer to misrepresent or misappropriate indigenous knowledge. Finally, this process affords the developer an excellent opportunity to grasp and understand the reasons for these concerns, especially those based on TEK, and the impacts proposed development activities will have on aboriginal lands and lifestyles.

Often, the priorities of industry, government, and aboriginal communities will be the same. Sometimes, however, they may differ. For example, maintaining a wilderness experience is important to many conservation groups, but it is frequently of less concern to aboriginal people who still derive an income and living from their lands. Where conflict exists, it is aboriginal people who should prevail. While the needs and interests of government and industry should carry some weight, the ranking of VECs and mitigation priorities should be determined by those most directly affected by development.

Phase Two: After those most directly affected by northern development have identified what is important to them and why, the developer should design measures to mitigate any potential negative effects on these VECs. This phase represents a concerted effort by the developer to address the environmental and socioeconomic concerns of aboriginal people identified in Phase One. Again, aboriginal people and their knowledge will play significant roles in designing such measures:

Because we look at the land differently from people who want to take resources out of it, our values reflect our responsibility to protect the land for ourselves and future generations. We feel that our values will be useful for identifying biophysical impacts. We also know that, among our traditional ways of working on the land, we can find ways to reduce some of these impacts. (Yellowknives Dene First Nation, 1995b:8)

Although, many concerns may be addressed as they are documented, some problems will undoubtedly require more time to solve satisfactorily, especially when there are knowledge gaps, or indigenous knowledge disagrees with Western scientific knowledge, or the experiences and informed opinions of aboriginal people differ. To obtain enough knowledge, either indigenous or scientific or both, to adequately address aboriginal concerns about proposed development, developers will require the understanding and cooperation of the aboriginal people of the region. This can be achieved by forming partnerships with aboriginal communities that will ensure a true balance of power in decision making and contribution of knowledge, especially in regard to identifying impacts and devising solutions for their mitigation.

Phase Three: The final stage in this process concentrates on indigenous knowledge relevant to monitoring and managing impacts on these VECs. Incorporating indigenous knowledge into the process of environmental assessment and management does not end with documenting that knowledge or with resolving the concerns of aboriginal people. Rather, these steps should initiate a program that involves aboriginal people, knowledge, and expertise fully and meaningfully in completing the environmental assessment process, monitoring VECs, and managing the long-term environmental and socioeconomic impacts of a project. Aboriginal representatives, not government or industry, should determine the extent of their own participation and the inclusion of their knowledge and expertise in this phase.

As proposed, these tasks constitute a multiphased approach designed to realize the full contributions of aboriginal people and their knowledge to EIA. The focus is not on traditional knowledge, as this emphasis creates a potentially exploitive situation that restricts the contributions of aboriginal people and their knowledge to environmental assessment and management. Rather, by identifying VECs, assessing impacts on these VECs, designing strategies for their mitigation, and participating in the long-term monitoring of impacts on these VECs, aboriginal people and their knowledge will assume full and integral roles in all stages of EIA.

\section{Aboriginal People and Indigenous Knowledge in Environmental Monitoring and Management}

Aboriginal people feel that their participation in environmental monitoring and management is warranted because they have a vested interest in and an in-depth knowledge of their lands and communities:

I think it's a good idea to have people involved ... because they're the ones that have the most to gain and the most to lose.... (McWilliam, 1995:9)

They understand the conditions and the environment better than somebody from down south. They have a better idea of the environmental conditions and the weather in general. (Metis elder; BHPDiamonds Inc. 1995: Appendix I-A7, p. 11)

The knowledge and insights of aboriginal people who have already experienced the impacts of mining and other industrial activities may be especially useful in predicting, assessing, and managing specific and cumulative impacts. Aboriginal people often possess a richer and more detailed understanding of the environment than outsiders, as they have had more extensive contact with the land. TEK may be especially valuable in distinguishing project-related impacts from natural changes in the environment. Because of their direct experiences on the land and their oral traditions, aboriginal elders often possess TEK that has been handed down through many generations. Thus, they may be in an especially favourable position to assess whether systemic changes in local environments are project-related or simply natural variation. Aboriginal elders with extensive local 
ecological knowledge may be especially cognizant of subtle, but significant, changes to ecosystem relationships. They may also know when environmental change may be more apparent rather than real.

An example from Tuktoyaktuk illustrates the last point. Under the auspices of the Arctic Environmental Strategy Contaminants Program, the Inuit Tapirisat of Canada conducted a study on local perceptions of contaminants in country food in three Inuit communities, including Tuktoyaktuk (Usher et al., 1995). Numerous community residents attributed recent changes perceived in the quality, abundance, and distribution of fish, caribou, ptarmigan, and berries to pollution by the petroleum industry. However, most elders, whose knowledge and experiences had the greatest time-depth, felt that these environmental changes were just part of the natural order of things.

Aboriginal elders and resource users may also know the location and timing of a host of significant biological events. Seasons are often defined precisely and locally by a complex series of predictable changes in weather, tides, breeding cycles, and migrations. For example, in some areas of the eastern Canadian Arctic, their knowledge of tides and lunar cycles allows the Inuit to forecast biological and behavioural changes in animal populations (M. Kilabuk, pers. comm., 1994). Another example of the temporal component of TEK comes from the Keewatin region of the Northwest Territories, where biologists in the 1970s claimed that the Kaminuriak herd had decreased to such an extent that it could no longer support existing levels of hunting by aboriginal people. Although aboriginal people disagreed, claiming that there were far more caribou in this herd than the number counted, strict hunting regulations were being considered when biologists discovered, in their next count, that this herd had increased by several orders of magnitude (Usher, 1993).

Monitoring of specific and cumulative impacts on VECs means establishing plans designed to maintain the integrity of these components. Often the richest and most detailed TEK is documented when aboriginal people can share this knowledge while engaged in the land-based activity in question. Because aboriginal people know this, they generally prefer to share their knowledge in the context of "doing" rather than "retelling." The contribution of aboriginal people to monitoring will be further enhanced when elders and resource users not directly involved in monitoring are consulted and their knowledge is brought to bear on the current status of environmental VECs. A developer's monitoring efforts must therefore include plans aimed at refining knowledge of VECs and their linkages through the use of TEK, and documenting baseline TEK on natural cyclical changes and variation in these ecosystem components and their relationships over a broad time scale.

An Example of the Way Things Could Be: Managing Caribou and Human Relationships in the Lac de Gras Area: Indigenous knowledge of the distributions, characteristics, and relationships of various aquatic features, terrestrial habitats, plants, and animals in a particular region can also provide effective strategies and shortcuts for developers wishing to maintain VECs and critical ecosystem relationships (Johannes, 1993). In regard to the Bathurst caribou, one of the key VECs identified in the context of BHP Diamonds Inc.'s environmental impact assessment, many aboriginal people were concerned not just about the individual effects on caribou of new roads, increased air and road traffic, oil or fuel spills, noise and air pollution, increased hunting pressure, and water contamination, but also about the cumulative effects of these impacts. The value of this caribou herd to the Dene of the region is evident in the following statement to the Federal Environmental Assessment Panel for the BHP Diamonds project:

\begin{abstract}
We have one of the largest caribou herds in the world who have always been here. Are we destined to experience the devastation that First Nations in the South have lived through with the decimation of their buffalo? When the caribou disappear, it is only a matter of time before we also disappear. (Erasmus, 1995:2)
\end{abstract}

Given the value of the Bathurst caribou herd to contemporary aboriginal society and economy in the region, it is particularly important to monitor the effects of mining activity on caribou during the spring and fall migrations, when they are travelling through the Lac de Gras area. Extensive monitoring will be needed to assess the full effects of mining on the broader patterns of caribou movement and behaviour in the region, especially with respect to grazing areas and migration routes. However, some of this work may be obviated by the use of indigenous knowledge and the fact that aboriginal resource users are particularly cognizant of the reproductive success of caribou as an indicator of cumulative stress:

\begin{abstract}
My concern is that we're going to end up with lessened caribou and their reproduction will probably decrease as the result of being stressed and being moved and whatever... And, like I said again, I'm not an expert on any of this, so I'm only guessing on what I have seen in the past. (McWilliam, 1995:5)
\end{abstract}

Indigenous people who depend upon caribou have extensive knowledge of the health of this animal and can determine, by examining the condition of caribou and observing their movements and behaviours, whether they are under stress. Seasonal observations and harvest assessments, including visual assessments of the internal organs of Bathurst caribou by the aboriginal people of the region could thus help determine the levels of stress to which this herd is subjected.

TEK research undertaken in the context of the BHP Diamonds Inc. Environmental Impact Statement (1995) has established that 1) the migratory patterns and behavior of the Bathurst caribou are locally unpredictable and highly variable from year to year; 2) two major migration corridors cross the Lac de Gras region, along the north and south sides of the lake; and 3) the area between the southeast end of Lac de Gras and the north end of MacKay Lake, known to the Dene as $E k^{\prime} a t i$, is attractive to both caribou and humans. 
Aboriginal people and their knowledge could contribute to managing the effects of mining activities on caribou by helping to 1) determine the importance of the Lac de Gras area to the Bathurst caribou herd over a broad time scale; 2) identify important migratory corridors and critical habitats within the project area; 3 ) determine the range of variability in the size and composition of caribou aggregations at specific times and locations; 4) identify specific spatial and temporal grazing patterns and the importance of various plant species to caribou in the area; 5) determine the effects of smoke and other man-made emissions on caribou behaviour (DCI, 1995b); and 6) enlist traditional methods to divert caribou from potentially threatening sites and situations. In regard to the last point, aboriginal people have been engaged to evaluate a number of diversionary tactics, both modern and traditional (BHP Diamonds Inc., 1995).

\section{Monitoring and Managing Social and Economic Impacts}

Environmental management for sustainable development in the North requires special attention to social, cultural, and economic VECs. The ways in which aboriginal people perceive, use, and allocate natural resources bear directly upon how they traditionally maintained or may wish to maintain their society and cultural identity. As hunting, fishing, trapping, and other land-based activities continue to secure and validate social relationships crucial to aboriginal survival, any environmental impact may also adversely affect social relationships (cf. Freeman et al., 1992). For example, social relations may be seriously strained if the Bathurst caribou herd is significantly reduced. The hunting and sharing of caribou remains one of the few traditional activities that aboriginal people continue to employ to "put food in the freezer," establish and renew social relationships, fulfill social obligations, and reaffirm their cultural identity and spiritual and physical connections to the land. The loss of this herd might prove devastating to aboriginal people who depend heavily upon it.

The environmental effects of proposed mines in the North will have social, cultural and economic repercussions in and among aboriginal communities. This would undoubtedly be so if aboriginal people were deprived of the opportunity to form productive social relationships within the context of land-based activities. However, the effects of increased personal income and family separation, the loss of youth and other productive people to the mines, and increased crosscultural interaction may have more immediate impacts that will require mitigation. In regard to the proposed BHP Diamonds mine, aboriginal people have suggested that community counsellors be hired to alleviate the social problems that could result from increased employment:

You are never gonna prevent them [social problems]. What you can do is help minimize them. I think if [BHP] are really serious about helping in the community and increasing productivity of their employees, [they should] hire a full-time family guidance counsellor. Somebody who's gonna go door to door and talk to all these people, when their husbands are out, to make sure everything's o.k. And go by their place twice a week or something and visit around people and say how's it going, you need anything or is there anything we can do to help you? ...That's what they're gonna need.... a full-time guidance counsellor because also this guidance counsellor could help with how to spend their money, help to deal with negative effects. (Adamache, 1995:8)

But, in aboriginal communities where employment opportunities are few, increased income may also have significant positive impacts, providing people with not only the income and opportunity to maintain their traditional land-based lifestyles, but a sense of purpose and self-esteem:

This [BHP] mine is going to help us socially. It will give us money to travel south and see the world. I have bought a house now. The mine has helped me to set higher social standards. I am going back to school. My self-esteem is higher....I like the feeling of independence. (BHP Diamonds Inc., 1995:Appendix IV-C2, p. 11)

In recognition of the effects, both positive and negative, that the NWT Diamonds Project may have on aboriginal communities, BHP has hired a family life educator to assist local efforts to deal effectively and productively with these effects (BHP Diamonds Inc., 1995). Eventually this work should allow aboriginal communities to identify the most appropriate and effective strategies to maximize benefits for family and community, while minimizing negative effects.

\section{Controlling the Research Agenda}

Federal environmental guidelines have placed northern developers in a difficult position by requiring that efforts to include traditional knowledge into EIA must satisfy aboriginal interests. Increasingly, research on aboriginal lands in the North is being controlled by aboriginal groups. And this is as it should be. For too long, outsiders have set the research agenda to satisfy their own needs and interests, rather than those of the people and communities that make this research possible. As noted above, the proprietary rights to the knowledge of aboriginal people and how it is collected, interpreted, and used rests in aboriginal hands alone. Participatory action research (PAR) has developed as a process to ensure that aboriginal communities control the local research agenda. PAR can also provide an excellent opportunity for young people to gain an understanding and appreciation of their culture, as well as the science and culture of researchers (Legat, 1994).

PAR is an important step in empowering aboriginal communities, for it can play a critical role in documenting and applying TEK. However, exclusive control by either party of the traditional knowledge research agenda in the context of EIA serves no one's interests. If the agenda is set by the developer, many of the fears expressed by aboriginal groups 
about the decontextualization and misuse of their knowledge will undoubtedly come to pass. On the other hand, if the aboriginal community maintains exclusive control over the TEK research agenda, dictating to developers what knowledge they may have, the latter may not be able to meet federal requirements or access that knowledge most useful for EIA. For instance, in the documenting of traditional knowledge, some community voices with much to contribute may be muted; the knowledge of elders may be favoured over that of other aboriginal people who have more direct experience with the possible effects of activities proposed by the developer, or men's knowledge may be favoured over women's. Just as developers cannot demand access to the knowledge they require from aboriginal people, the latter should not dictate exclusively to developers the research agenda. Thus, as long as the requirement of traditional knowledge remains in federal guidelines, an uneasy relationship and power struggle will prevail between those who have the knowledge and those who need it.

One way to resolve this dilemma is to abandon the concept of traditional knowledge in EIA in favour of that of indigenous knowledge, while letting aboriginal people assume responsibility for identifying, assessing, and monitoring effects on their lands and lifestyles. Mitigation, contingent on aboriginal approval, should be the developers' responsibility. In this way, all the knowledge that aboriginal people possess, not just traditional knowledge, can potentially be brought to bear on environmental assessment and management. Moreover, a productive partnership, with a true balance of power between developers and aboriginal people, will be forged, fostered, and maintained.

\section{TRADITIONAL KNOWLEDGE AND WESTERN SCIENTIFIC KNOWLEDGE SYSTEMS}

Viewing traditional knowledge as one component, albeit an integral one, of indigenous knowledge was not intended to devalue its potential contributions to EIA. Rather, it was to elucidate a process for maximizing the full contributions of aboriginal people and their entire knowledge base to all stages of environmental assessment and management. Traditional knowledge is the intellectual product of countless generations of direct observation and intuitive experience handed down through oral tradition. As such, it has a vital role to play in EIA, but only in the broader context of the application of indigenous knowledge, which is the articulation and frequently the synthesis of traditional and nontraditional knowledge.

Many definitions have been advanced for traditional knowledge. However, for northern aboriginal people whose cultures and identities are still constructed from their physical and spiritual connection to the land, definitions are less important than either the right to practise what they know and hold to be true, or the ability to participate in decisions that affect their future. Unfortunately, these are being compromised by many factors, including the imposition of Western science on aboriginal people (Gamble, 1986; Cashman, 1991). Although traditional knowledge and Western scientific knowledge are products of a similar intellectual process of creating order out of disorder (Berkes, 1993), both are culturally scripted and biased. For example, a growing body of literature describes the ways in which gender-based dominance relationships and Western values have been programmed into the production, scope, and structure of scientific knowledge (see Cashman, 1991 for sources). In other words, Western scientific knowledge is generated largely by and for males cultured in the scientific tradition. As a result, the voices of women and aboriginal peoples are often muted, and their knowledge systems subsequently pre-empted by scientific knowledge. This is unfortunate, as alternative realities can provide unique perspectives and insights on environmental assessment and management. Realizing that different cultures have different ways of understanding, perceiving, experiencing, and, in sum, defining reality (Cashman, 1991:49) is fundamental to understanding the strengths of traditional knowledge and Western scientific knowledge, and thus their potential contributions to environmental management.

Just as it is difficult to separate traditional knowledge from its cultural context, Western scientific knowledge cannot be divorced from the broader context in which it operates. Thus, clarification of the differences between traditional and Western scientific knowledge must be preceded by a discussion of the broader contexts of each. The philosophical, cultural, social, and other dimensions that distinguish these contexts and give meaning and value to each system of knowledge are presented in Table 1.

These are generalizations to be sure, and not all people with each worldview possess the same combinations of features that make up their frames of reference. Yet, many of these features are inseparable and only derive meaning and value from within their respective contexts. Thus, these worldviews are internally coherent, and their features form a system. One can appreciate how, for example, materialism and wealth accumulation go hand in hand with saving and concern for the future, but not with sharing, wealth distribution, and an emphasis on the present. While these differences are perhaps relevant to understanding other worldviews, it is obvious that traditional and scientific knowledge are constructed from different contextual frameworks.

The importance of context for understanding and communicating knowledge in northern aboriginal society cannot be overstated. As meaning for many aboriginal people is derived as much from the context of communication itself as from the information communicated, it is important to understand the differences between what is being communicated and the situation in which the communication takes place. For many aboriginal people, experience is knowledge and knowledge is experience. Thus, knowledge has to be constructed for each individual, and is not easily shared among individuals unless there is a mutual understanding and appreciation of that experience. This is why, for example, it is difficult for northern aboriginal people to communicate to outsiders what traditional knowledge is, and why it is equally as hard for 
TABLE 1. A sample of features that distinguish the worldviews in which traditional knowledge and Western scientific knowledge are embedded. Adapted and expanded from Lalonde (1993), Tanner (1979), and Wolfe et al. (1992), among others.

\begin{tabular}{|c|c|}
\hline Traditional Aboriginal Values and Orientations & Western Values and Orientations \\
\hline individual, extended family, and group concern & individual and immediate family concern \\
\hline small group size & large group size \\
\hline cooperation & competition \\
\hline holistic view of nature & homocentric view of nature \\
\hline partnership with nature & exploitation of nature \\
\hline renewable resource economy & nonrenewable resource economy \\
\hline sharing by all of land and resources & private ownership of land and resources \\
\hline sharing and wealth distribution & saving and wealth accumulation \\
\hline focus on the present & focus on the future \\
\hline nonmaterialistic orientation & materialistic orientation \\
\hline time measurement in natural cycles, e.g., seasons & time measurement in small, arbitrary units \\
\hline practical, intuitive thinking & theoretical thinking, prone to abstraction \\
\hline face-to-face government and politics & representative democracy \\
\hline egalitarian organization & hierarchical organization \\
\hline age and wisdom valued & youth and beauty valued \\
\hline high group esteem, lower self-esteem & high self-esteem, lower group esteem \\
\hline modesty and reserve & confidence and noisiness \\
\hline patience: problems will be resolved in time & impatience: problems resolved quickly \\
\hline
\end{tabular}

non-aboriginals to understand and appreciate how that knowledge can be used in environmental assessment and management. This is also perhaps why aboriginal people have been reluctant generally to share their experiential observations with outsiders.

Northern aboriginal societies can be categorized as possessing "high-context" communication systems as they rely more on context for meaning (Hall, 1977). Conversely, Western society has been described as being "low-context," because it is more reliant on information to provide meaning and understanding. Anthropologists sometimes experience this dilemma while interviewing an aboriginal elder, when an interpreter translates a lengthy response to a question in a few words. What is frequently translated in such situations is only the information content within the communication, which the interpreter feels answers the question of the non-aboriginal, but not the context which gives meaning and value to such information from the perspective of the speaker. This is another reason why the potential to misrepresent or misuse traditional knowledge by those who do not understand or appreciate the context in which it is embedded is great.

Traditional knowledge differs from Western scientific knowledge in a number of substantive ways. Many anthropologists (e.g., Wolfe et al., 1992; Berkes, 1993; Lalonde, 1993) have concluded that traditional knowledge, in comparison with scientific knowledge, is:

- intuitive and holistic, as opposed to analytical, reductionistic and law-seeking

- qualitative, as opposed to quantitative

- moral, as opposed to supposedly value-free

- subjective and experiential, as opposed to objective and positivist

- inclusive, as opposed to decisive

- inconclusive and internally differentiating, as opposed to conclusive and externally differentiating

- slow to create, as opposed to fast and selective
- broad in time and narrow in geographic focus, as opposed to narrow in time and broad in geographic focus

- open to spiritual explanation, as opposed to mechanistic explanation.

There are exceptions to these generalizations. For example, ecological sciences often use holistic approaches, and occasionally produce diachronic data relevant to understanding natural variation (Berkes, 1993). However, most aboriginal hunters do not commit "hard" numbers to memory, since knowing the precise number of animals present has not been considered necessary for the success of the hunters or their groups (Usher and Wenzel, 1987). Very precise observations about the condition, health, and individual and group behaviours of animals, on the other hand, are more important knowledge for hunters to obtain. Those qualitative factors that affect success or failure of hunting, rather than quantitative measurements of animals themselves, have traditionally been considered important (Usher and Wenzel, 1987). Thus, hunters often acquire extensive knowledge about specific species and all the variables that influence their availability, behaviours, movements, and interrelationships within the surrounding environment. It is no longer true, if it ever was true in environmental assessment, that the only things that count are those things that can be counted. Numerical and other "hard" data represent only a small portion of the total body of knowledge that aboriginal resource-users can observe, commit to memory, and contribute to sound environmental management strategies.

That said, many aboriginal peoples are reluctant to generalize readily about the natural world of which they are a part. Their experience with the complexity of animals and knowledge of the dynamics of ecosystems tells them that such exercises are futile indeed. While TEK is markedly slower than science in terms of the speed at which knowledge is constructed, any environmental facts which aboriginal people 
hold to be true, or "truths," are generally regarded to be just that. "Rules of thumb" and general principles for living developed from these truths and enforced by social and cultural means are in many ways just as good as scientific prescriptions (Gadgil and Berkes, 1991).

On the basis of their accumulated knowledge and experiences, aboriginal people have developed an extensive body of informal or intuitive knowledge that can be brought to bear on environmental assessment and management. The strengths of indigenous knowledge systems in EIA lie in the fact that they are designed to incorporate complexity, expand detail, and include, rather than eliminate, phenomena that cannot be explained (Wolfe et al., 1992). Rather than reducing information into condensing or summarizing categories, indigenous knowledge sees inclusive groupings with internal differentiation (Wolfe et al., 1992). The perceptive documentation and use of TEK can thus provide new insights into key VECs and ecosystem relationships, streamlining research efforts and saving money in the long run. Finally, aboriginal people are often able to assess the true costs and benefits of development better than outsiders because of their extensive, time-tested, in-depth knowledge of the natural environment (Berkes, 1993).

However, indigenous knowledge and Western science are complementary, not replacements for each other (Berkes, 1993), a fact recognized by many aboriginal people:

Today the world is different than it was when the Elders were young. Aboriginal people need to create a new balance that incorporates significant scientific knowledge. Southern scientists cannot simply impose their views. They must be interlinked. Water chemistry is an area where scientists know more than we do. How dry is dry? How wet is wet? Scientific knowledge is good at quantifying impacts. It depends on the question what the appropriate blend of traditional and scientific knowledge should be at any given time. (BHP Diamonds Inc., 1995: Appendix IV-C2, p. 25)

The analytical capabilities of Western science are invaluable for assessing and managing environmental impacts. The ability of scientists to reduce the number of variables involved (even though such reduction may conflict with aboriginal perceptions), quickly identify impacts and isolate their causes, and measure and manage change are some of the greatest strengths science can bring to EIA. Nonetheless, the practical difficulties of applying science in a rigorous manner are numerous. Some of the more obvious are 1) the integrated nature of environmental issues versus the artificial fragmentation of areas of responsibility, knowledge, and action; 2) the tendency to substitute observation and data for understanding and wisdom; and 3) the reluctance to deal with the difficult problem of relating natural processes over a range of time and space scales (Roots, 1994).

At the same time, since indigenous knowledge generation does not use the same methods of data collection, storage, analysis, and interpretation as scientific knowledge, scientists often have great difficulty in acknowledging the validity of knowledge generated in other ways and rethinking groupings so as to uncover basic organizing principles which are unfamiliar (Wolfe et al., 1992).

\section{The Acceptance of Scientific Knowledge by Aboriginal People}

At this point, the role of Western scientific knowledge in addressing and mitigating the concerns that aboriginal people might have about proposed developments should be clarified. Western scientific knowledge is not inimical to aboriginal worldviews, but the potential for incongruence is considerable. Nonetheless, traditional knowledge can inform scientific knowledge, and vice versa. In regard to the possible articulation of TEK and environmental science, when aboriginal hunters say that animals will continually be replenished if hunted, they speak to facts that are well-established in the biological sciences. For example, Inuit believe that beluga belonging to hunted populations will grow faster, have more blubber, and have less disease than those associated with nonhunted populations (DFO, 1994). Aboriginal people may feel comfortable with scientific explanation if it does not conflict with or undermine their knowledge.

The potential for aboriginal people to accept or reject social scientific explanation of their social problems and concerns is just as great. However, this depends upon the scientific paradigm being proposed. Traditional approaches have failed largely because they focused on the individual as the source of his or her self-defeating behaviours, rather than on the oppressive social, economic, and political conditions in which many aboriginal people often have to live (Morgaine, 1992). Social science approaches that view aboriginal people as capable of selecting and controlling any social changes to be made, i.e, of becoming architects in reconstructing these conditions, are more likely to gain acceptance (Morgaine, 1992).

\section{CONCLUSION}

The intention of this paper was not to debase traditional knowledge. Rather, it was to advance a process by which to maximize its full contributions, and those of aboriginal people and all their knowledge, to EIA. The potential to misrepresent and misuse traditional knowledge is great when that knowledge is separated from the broader system of knowledge and the cultural context that give it meaning and value. Thus, the concept of traditional knowledge in EIA makes it impossible to avoid problems for people who possess this knowledge and for developers who are required to consider it when assessing the impacts of their activities on aboriginal lands, economies, and societies. As long as this requirement remains in federal guidelines, an uneasy relationship will prevail between those who have the knowledge and those who need it. One way of resolving this conundrum is not to focus on traditional knowledge per se, but to incorporate the 
entire knowledge system of aboriginal people into all stages of EIA, while accepting them as integral players in the identification, assessment, mitigation, and monitoring of environmental and socioeconomic impacts.

Increasingly, the value of traditional knowledge in northern environmental assessment is being recognized. However, realization of its role in EIA will remain elusive if it continues to be taken out of context and aboriginal people continue to be regarded as just another "stakeholder." This is why it is incumbent upon government and industry to abandon old concepts and explore new ways to involve aboriginal people and incorporate their knowledge into EIA. Only through the formation of true power-sharing relationships, in which both parties provide equal contributions of knowledge and expertise to apply this knowledge, will aboriginal people and industry mutually benefit from northern development.

\section{ACKNOWLEDGEMENTS}

I wish to thank Dr. Milton Freeman for his continuing support and encouragement during the formative stages of this paper. Recognition is also due to Clem Pelletier, Bruce Turner, and other BHP and Rescan employees and staff for their assistance in carrying out the traditional knowledge component of BHP Diamonds Inc.'s Environmental Impact Statement. For their help in facilitating the documentation of the concerns that various aboriginal people and groups had about the proposed NWT Diamonds Project, I would like to thank Angel Kuliktana, Chris Hanks, and Gordon Lennie. A special thanks is extended to Dene National Chief Bill Erasmus for allowing me to access the traditional land-use information contained within the Dene Mapping Project database. The comments of Drs. F. Berkes, Milton Freeman, and Karen McCullough, and of Martha Johnson and two anonymous reviewers on an earlier draft of this paper have helped to sharpen the final product. Finally, I would like to thank those Dene, Inuit, and Metis who voiced their concerns and shared their knowledge in the context of BHP's traditional knowledge research for its Environmental Impact Statement.

\section{REFERENCES}

ADAMACHE, B. 1995. Transcribed interview for BHP Diamonds Inc. traditional knowledge project. Available from Kitikmeot Inuit Association, Coppermine, Northwest Territories X0E 0E0, Canada.

BERKES, F. 1993. Traditional ecological knowledge in perspective. In: Inglis, J.T., ed., Traditional ecological knowledge: Concepts and cases. Ottawa: Canadian Museum of Nature. 1-9.

BHP DIAMOND MINE ENVIRONMENTAL ASSESSMENT PANEL. 1995. Final guidelines for the preparation of an environmental impact assessment. Available from BHP Diamond Mine Environmental Assessment Panel, Information Office, 2nd floor, 5-5120 49th St., Yellowknife, Northwest Territories X1A 1P8, Canada.

(BHP) BHP DIAMONDS INC. 1995. NWT Diamonds project: Environmental impact statement. Vancouver: BHP Diamonds
Inc. and Dia Met Minerals. 4 volumes and 4 appendices. Available from BHP Diamonds Inc., 1050 West Pender St., Suite 1600, Vancouver, British Columbia V6E 3S7, Canada.

CASHMAN, S. 1991. Systems of knowledge as systems of domination: The limitations of established meaning. Agriculture and Human Values (Winter-Spring) 1991:49-58.

(DCI) DENE CULTURAL INSTITUTE. 1995a. Written submission to the BHP Diamond Mine Environmental Assessment Panel, 6 April 1995. Available from BHP Diamond Mine Environmental Assessment Panel, Information Office, 2nd floor, 5-5120 49th St., Yellowknife, Northwest Territories X1A 1P8, Canada.

- 1995b. Tlicho Nde: The importance of knowing. Report prepared for the Dogrib Treaty 11 Council and BHP Diamonds Inc., June 1995. In: BHP Diamonds Inc. 1995: Appendix I-A7. (DFO) DEPARTMENT OF FISHERIES AND OCEANS. 1994. Co-management plan for southeast Baffin beluga. Winnipeg: Freshwater Institute, Department of Fisheries and Oceans.

ERASMUS, B. 1995. Written presentation to the BHP Diamond Mine Environmental Assessment Panel, Yellowknife, N.W.T. Available from BHP Diamond Mine Environmental Assessment Panel, Information Office, 2nd floor, 5-5120 49th St., Yellowknife, Northwest Territories X1A 1P8, Canada.

FREEMAN, M.M.R., WEIN, E.E., and KEITH, D.E. 1992. Recovering rights: Bowhead whales and Inuvialuit subsistence in the western Canadian Arctic. Edmonton: Canadian Circumpolar Institute and Fisheries Joint Management Committee.

GADGIL, M., and BERKES, F. 1991. Traditional resource management systems. Resource Management and Optimization 18:127-141.

GAMBLE, D. 1986. Crushing of cultures: Western applied science in northern societies. Arctic 39:20-23.

GOMBAY, N. 1995. Bowheads and bureaucrats: Indigenous knowledge and natural resource management in Nunavut. Unpubl. Master's thesis, Environmental and Resource Studies, University of Waterloo.

HALL, E.T. 1977. Beyond culture. Garden City, New York: Anchor Press and Doubleday.

(ICC) INUIT CIRCUMPOLAR CONFERENCE. 1993. The participation of indigenous people and the application of their environmental and ecological knowledge in the Arctic Environmental Protection Strategy: A report on findings. Ottawa: Inuit Circumpolar Conference, Canada.

1994. Circumpolar sustainable development. Ottawa: Inuit Circumpolar Conference, Canada.

JOHANNES, R.E. 1993. Integrating traditional ecological knowledge and management with environmental impact assessment. In: Inglis, J.T., ed. Traditional ecological knowledge: Concepts and cases. Ottawa: Canadian Museum of Nature. 33-39.

LALONDE, A., 1993. African indigenous knowledge and its relevance to sustainable development. In: Inglis, J.T., ed. Traditional ecological knowledge: Concepts and cases. Ottawa: Canadian Museum of Nature. 55-62.

LEGAT, A. 1994. Participatory action research in Rae Lakes, N.W.T.: The traditional government project. Information North 20(2):1-4. 
McWILLIAM, I. 1995. Transcribed interview for BHP Diamonds Inc. traditional knowledge project. Available from Kitikmeot Inuit Association, Coppermine, Northwest Territories X0E 0E0, Canada.

MIGWI, J. 1995. Verbal presentation to the BHP Diamond Mine Environmental Assessment Panel, Rae-Edzo, N.W.T. Available from BHP Diamond Mine Environmental Assessment Panel, Information Office, 2nd floor, 5-5120 49th St., Yellowknife, Northwest Territories X1A 1P8, Canada.

MIYOK, J.R. 1995. Transcribed interview for BHP Diamonds Inc. traditional knowledge project. Available from Kitikmeot Inuit Association, Coppermine, Northwest Territories X0E 0E0, Canada.

MORGAINE, C.A. 1992. Helping people change themselves: A critical approach to family life education. In: Riewe, R., and Oakes, J., eds. Human ecology. Edmonton: Canadian Circumpolar Institute. 69-79.

ROOTS, F. 1994. Some concepts and issues surrounding the place of science in assessment of impacts on the environment. In: Higgs, E., Richardson, M., and Riewe, R., eds. The role of science in environmental impact assessment. Edmonton: Workshop proceedings published by Athabasca University and the Canadian Circumpolar Institute. 1-10.

TANNER, A. 1979. Bringing home animals: Religious ideology and mode of production of the Mistassini Cree hunters. St. John's, Newfoundland: Memorial University Press.

UNITED NATIONS CONFERENCE ONENVIRONMENT AND DEVELOPMENT, 1992. Agenda 21. New York: The United Nations Conference on Environment and Development.
USHER, P.J. 1993. The Beverly-Kaminuriak caribou management board: An experience in co-management. In: Inglis, J.T., ed. Traditional ecological knowledge: Concepts and cases. Ottawa: Canadian Museum of Nature. 111-120.

USHER, P.J., and WENZEL, G. 1987. Native harvest surveys and statistics: A critique of their construction and use. Arctic 40: $145-160$.

USHER, P.J., BAIKIE, M., DEMMER, M., NAKASHIMA, D., STEVENSON, M.G., and STILES, M. 1995. Communicating about contaminants in country food: The experience in aboriginal communities. Available from Inuit Tapirisat of Canada, 170 Laurier St. West, Suite 510, Ottawa, Ontario K1P 5V5, Canada. WOLFE, J., BECHARD, C., CIZEK, P., and COLE, D. 1992. Indigenous and Western knowledge and resource management systems. Guelph, Ontario: University School of Rural Planning and Development, University of Guelph.

(WCED) WORLD COMMISSION ON ENVIRONMENT AND DEVELOPMENT. 1987. Our common future. New York: World Commission on Environment and Development.

YELLOWKNIVES DENE FIRST NATION. 1995a. Saving our community cultural heritage resources: Policy guidelines for Yellowknives Dene traditional knowledge. Yellowknife, N.W.T.: Yellowknives Dene First Nation.

1995b. Evaluation of environmental impact statement for BHP-Dia Met proposed diamond mines project on Yellowknives Dene traditional lands near Lac de Gras, 23 October 1995. Yellowknife, N.W.T.: BHP Diamond Mine Environmental Assessment Panel, Information Office. 